\title{
Leveraging public harvest to reduce invasive hybridization in Yellowstone National Park: field identification and harvest of cutthroat $\times$ rainbow trout hybrids
}

\author{
Kurt C. Heim $\mathbb{~}$ - Thomas E. McMahon - Brian D. Ertel - Todd M. Koel
}

Received: 1 July 2019/Accepted: 2 May 2020/Published online: 19 May 2020

(C) The Author(s) 2020

\begin{abstract}
Leveraging public harvest can be a costeffective invasive species management tool, but target taxa must be correctly identified and removed at rates that achieve biological objectives. We explored the potential role of recreational anglers to curtail expanding hybridization between invasive rainbow trout (Oncorhynchus mykiss; RT) and native Yellowstone cutthroat trout (O. clarkii bouvieri; YCT) in the Lamar River watershed in Yellowstone National Park. We sought to (1) develop a hybrid identification key that could be used by anglers and (2) estimate angler participation, catch, and potential exploitation rates.
\end{abstract}

Electronic supplementary material The online version of this article (https://doi.org/10.1007/s10530-020-02280-y) contains supplementary material, which is available to authorized users.

K. C. Heim (凹) · T. E. McMahon

Ecology Department, Fish and Wildlife Ecology and Management Program, Montana State University, Post Office Box 173460, Bozeman, MT 59717, USA e-mail: Kurtcheim@gmail.com

Present Address:

K. C. Heim

School of Marine and Atmospheric Sciences, Stony Brook University, Stony Brook, NY, USA

B. D. Ertel · T. M. Koel

U.S. National Park Service, Yellowstone Center For

Resources, Native Fish Conservation Program,

Post Office Box 168, Yellowstone national Park,

WY 82190, USA
We assessed seven morphological features of trout in the field ( $n=251,15$ locations) and collected fin clips to estimate RT ancestry proportion using genetic analysis. An identification key was built using recursive partitioning to objectively distinguish YCT from RT and hybrids. A single-choice dichotomous key (white pelvic fin tip present/absent) correctly classified $93 \%$ of fish as native (YCT) or containing RT ancestry (RT or hybrid). Success increased to $97 \%$ when a second criterion was added (head spot count $\geq 6$ ). Using angler surveys (2013-2017), we estimated that 10,000 anglers catch 50,000 trout annually. In a popular road-accessible area, most trout are probably caught and released $\sim 5$ times each year. The combination of high angler participation, substantial annual catch, and an accurate and easy to use identification method indicate that leveraging public harvest is a promising management tool. Invasive hybridization is a global conservation issue threatening many native taxa; this case study highlights some factors for resource managers to consider prior to implementing public harvest regulations and the benefits of standardized keys to distinguish hybrids in the field.

Keywords Public harvest - Invasive hybridization and introgression - Cutthroat trout - Invasive species management $\cdot$ Selective removal $\cdot$ Hybrid identification 


\section{Introduction}

Early detection and eradication of new invaders is ideal, but when eradication is not an option, maintenance control is often used to control invasive species once they have become established (Mack et al. 2000). A variety of physical, chemical, and biological methods can be used to mitigate negative impacts to native taxa (Frazer et al. 2012; Simberloff 2014). To be effective, a sufficient number of invasive organisms must be removed, yet, costs of achieving such numbers can be substantial, required in perpetuity, and may deprive funding from other conservation opportunities (Pimentel et al. 2005; Simberloff 2014). Thus, careful consideration is required before implementing a maintenance removal program.

Hunting and fishing for invasive animals can be used to reduce populations at little cost to agencies while providing recreation and outreach opportunities (Nuñez et al. 2012). For example, a successful campaign promoting spearfishing for invasive lionfish (Pterois spp.) reduced populations and predation on native fishes (Frazer et al. 2012). Lionfish are excellent table fare and can be marketed by fisherman, which has provided incentive for participation (Nuñez et al. 2012). Agency supported bounty programs are also used to bolster participation by rewarding participants monetarily for each invasive individual removed (Mack et al. 2000; Flinders et al. 2016). Such approaches, however, can have negative consequences. For example, in Australia there is public interest and participation in invasive cane toad (Rhinella marina) removal, but distinguishing cane toads from native toads can be challenging and some native individuals are inadvertently killed (Somaweera et al. 2010). Though public harvest can be a powerful tool, it will only be useful if target species can be identified accurately.

Field identification of non-native species can complicate maintenance control efforts, especially when invading species hybridize with native taxa further convoluting identification (Meyer et al. 2017a). If hybrids between introduced and native taxa are fertile, non-native genes can spread across the native species through introgressive hybridization (Allendorf et al. 2001). Such cases generate challenges for resource managers tasked with conserving the genetic integrity of native taxa. Hybrids may be difficult or impossible to identify in the field, necessitating costly and time-consuming molecular genetic methods to assess population status (Allendorf et al. 2001). Invasive hybridization is a conservation issue particularly common in the fishes because eggs are fertilized externally, and pre-zygotic isolating mechanisms are often weak between related taxa (Allendorf and Leary 1988).

One of the greatest threats to native cutthroat trout (Oncorhynchus clarkii spp.) is invasive hybridization with non-native rainbow trout $(O$. mykiss, RT). The widespread introduction of RT has contributed to the decline of all cutthroat trout subspecies in western North America (Allendorf and Leary 1988), and hybridization can proceed until pure native genotypes are replaced by hybrids (Allendorf et al. 2001). One subspecies, the Yellowstone cutthroat trout $(O . c$. bouvieri, YCT), is extirpated from $58 \%$ of the historical native range, and only $28 \%$ of the remaining populations are non-hybridized (Gresswell 2011). These genetically unaltered populations are considered the highest conservation priority, and various approaches are being used to protect them.

Management actions to conserve YCT include isolation of populations from hybrid sources using barriers, chemical removal of non-native source populations, and selective removal of hybrids and RT (Al-Chokhachy et al. 2014; Kovach et al. 2018). When a population has not yet become a hybrid swarm (i.e., all fish are hybrids), selective removal can curtail the further loss of native genotypes (Al-Chokhachy et al. 2014; Kovach et al. 2018). This can be advantageous as compared to complete eradication with chemical treatments and re-stocking native trout, because the local adaptations of the native population can be conserved. However, a long history of failed attempts to control invasive salmonids has shown that capturing sufficient numbers of fish to effect a biological change requires substantial effort, particularly in large streams (Hansen et al. 2019). Because YCT, RT, and their hybrids are highly regarded sport fish (Quist and Hubert 2004), leveraging public harvest could be a useful strategy to supplement removal efforts by management agencies (Flinders et al. 2016). Selective removal will be effective only if hybrids can be easily and reliably distinguished from native taxa and removal rates are high enough to achieve biological or genetic objectives.

We addressed these two uncertainties in the Lamar River watershed of Yellowstone National Park (YNP), 
which supports one of the few remaining metapopulations where large, migratory, non-hybridized YCT are still present. The extensive fluvial connectivity of this system promotes important life-history diversity, yet, also makes it vulnerable to upstream invasion of RT and RT $\times$ YCT hybrids $($ CTX) which are now common in the lower watershed and appear to be increasing in frequency upstream (Ertel et al. 2017,
Fig. 1). This watershed is also a premier fly-fishing destination, drawing anglers from around the world. In 2013, YNP implemented mandatory harvest regulations for RT (but not CTX) to engage the public in active management efforts. Regulations specified that all fish with red lower jaw pigmentation (i.e., a "cutthroat" slash) were protected; however, a recent study in Idaho found that about $50 \%$ of non-hybridized

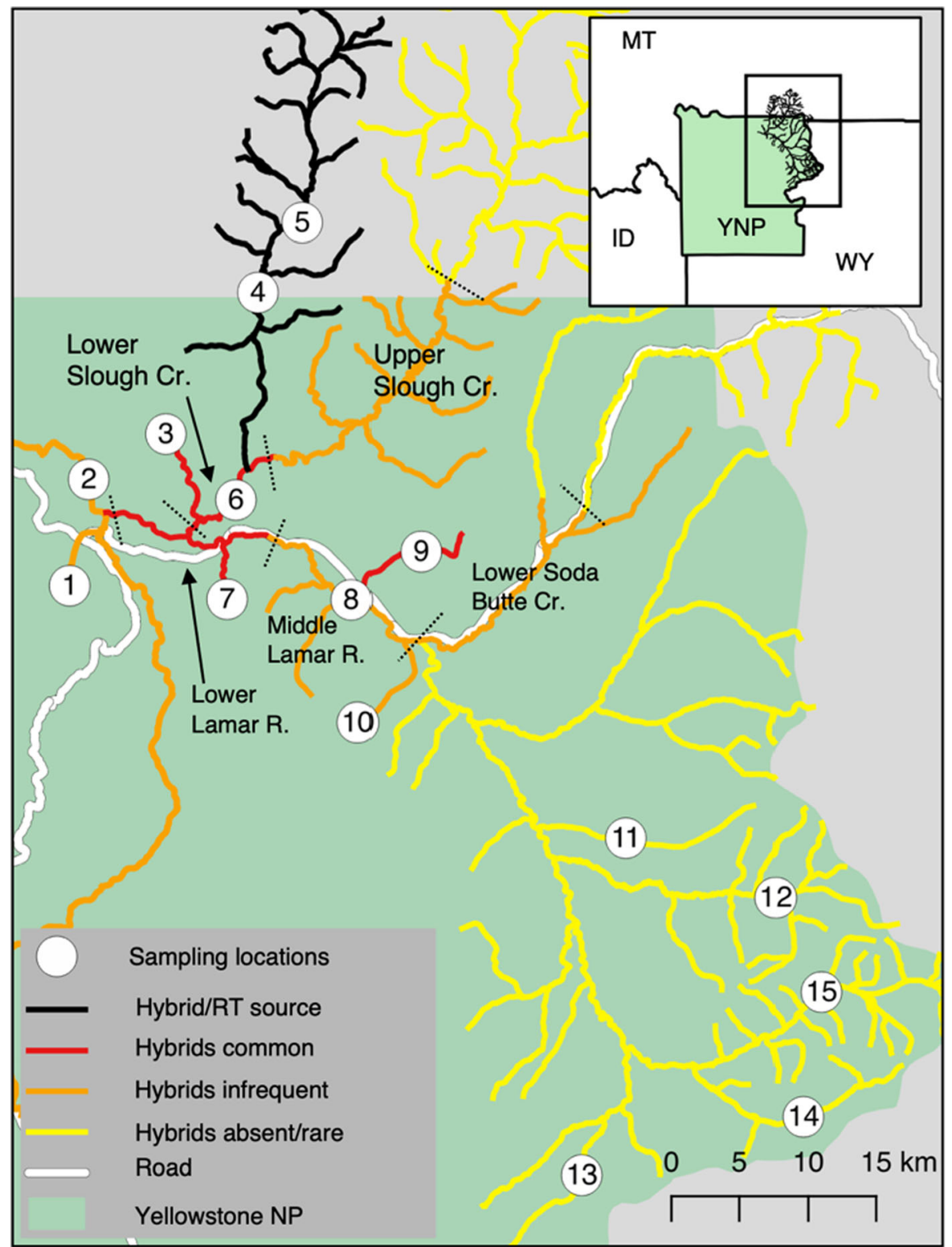

Fig. 1 The Lamar River watershed in Yellowstone National Park, depicting the general frequency of non-native and hybrid trout, reaches designated for estimating angler catch (named with black font, separated by dotted lines), and sampling sites where fish were collected for genotype-phenotype comparisons. Sample locations correspond with Table 1 
Table 1 Number of Yellowstone cutthroat trout (YCT), rainbow trout $(\mathrm{RT})$, and $\mathrm{YCT} \times \mathrm{RT}$ hybrids (CTX) used for genotype-phenotype and Hidden Creek are unofficial names that describe small, unnamed tributaries. Collection site number correspond with Fig. 1 comparison. Ditch Creek

\begin{tabular}{|c|c|c|c|c|}
\hline Area & Collection site & YCT & CTX & RT \\
\hline \multirow[t]{2}{*}{ Not in Lamar watershed } & 1. Ditch Creek & 22 & 1 & 0 \\
\hline & 2. Yellowstone River & 1 & 0 & 0 \\
\hline \multirow[t]{5}{*}{ Lower watershed } & 3. Hidden Creek & 2 & 33 & 2 \\
\hline & 4. Buffalo Fork Creek & 0 & 0 & 20 \\
\hline & 5. Hidden Lake & 0 & 0 & 21 \\
\hline & 6. Slough Creek & 0 & 4 & 0 \\
\hline & 7. Crystal Creek & 1 & 13 & 0 \\
\hline \multirow[t]{3}{*}{ Middle watershed } & 8. Lamar River (middle) & 1 & 0 & 0 \\
\hline & 9. Rose Creek & 1 & 3 & 0 \\
\hline & 10. Chalcedony Creek & 2 & 0 & 0 \\
\hline \multirow[t]{6}{*}{ Upper watershed } & 11. Calfee Creek & 25 & 0 & 0 \\
\hline & 12. Miller Creek & 23 & 1 & 0 \\
\hline & 13. Mist Creek & 30 & 0 & 0 \\
\hline & 14. Lamar River (upper) & 15 & 0 & 0 \\
\hline & 15. Little Lamar River & 30 & 0 & 0 \\
\hline & Totals & 153 & 55 & 43 \\
\hline
\end{tabular}

\section{Methods}

RT had faint cutthroat slashes, as did nearly $90 \%$ of all CTX (Meyer et al. 2017a). Therefore, if trout in the Lamar River had similar phenotype to genotype relationships, then regulations enacted in 2013 were protecting a majority of the fish the managers wished to remove. Fortunately, this same study found that white pigmentation on fin tips is reliably absent from YCT (99.5\%), but present in $80 \%$ and $57 \%$ of $\mathrm{F} 1$ and post-F1 hybrids, and $100 \%$ of RT. Therefore, in 2017 mangers in YNP updated regulations to include mandatory harvest of field identifiable CTX, suggesting the presence of a white fin tips as a useful feature to guide identification. Although the results of Meyer et al. (2017a) provide a useful guide for morphological identification in YNP, wide-ranging patterns in pigmentation are well documented in salmonids (Nicieza 1995; Seiler et al. 2009), substantiating the need for local validation of phenotypic criterion for identification. The objectives of our study were to: (1) develop a simple but precise dichotomous identification key that could be used by anglers in the Lamar River and (2) estimate angler participation, catch, and potential CTX exploitation rates that could help reduce RT and CTX abundance.
Study area

The Lamar River watershed encompasses an area of $1731 \mathrm{~km}^{2}$ and is mostly within YNP (Fig. 1). A concurrent research project evaluated the spatial distribution of hybridization in the watershed (Heim et al. in press) and results of this study are summarized in Fig. 1. Briefly, Buffalo Fork Creek is considered the primary source from which RT disperse to interbreed with native YCT, and hybridization is prevalent in several spawning populations in the lower watershed and Rose Creek in the middle watershed (Fig. 1). Hybridization has not been detected in many tributaries in upper Slough Creek and the Lamar River near their headwaters.

Fish sampling and morphological assessment

Trout $(n=251)$ from 15 sites were assessed for morphology and genotyped to estimate individual proportion of RT ancestry (Fig. 1, Table 1). Fish were sampled from June to September in 2016, and from March to August in 2017 using angling $(n=45)$, backpack electroshocking $(n=189)$, and gillnets $(n=17)$. Although sampling was not conducted randomly across space, during a given sampling event fish were randomly selected for genetic and 


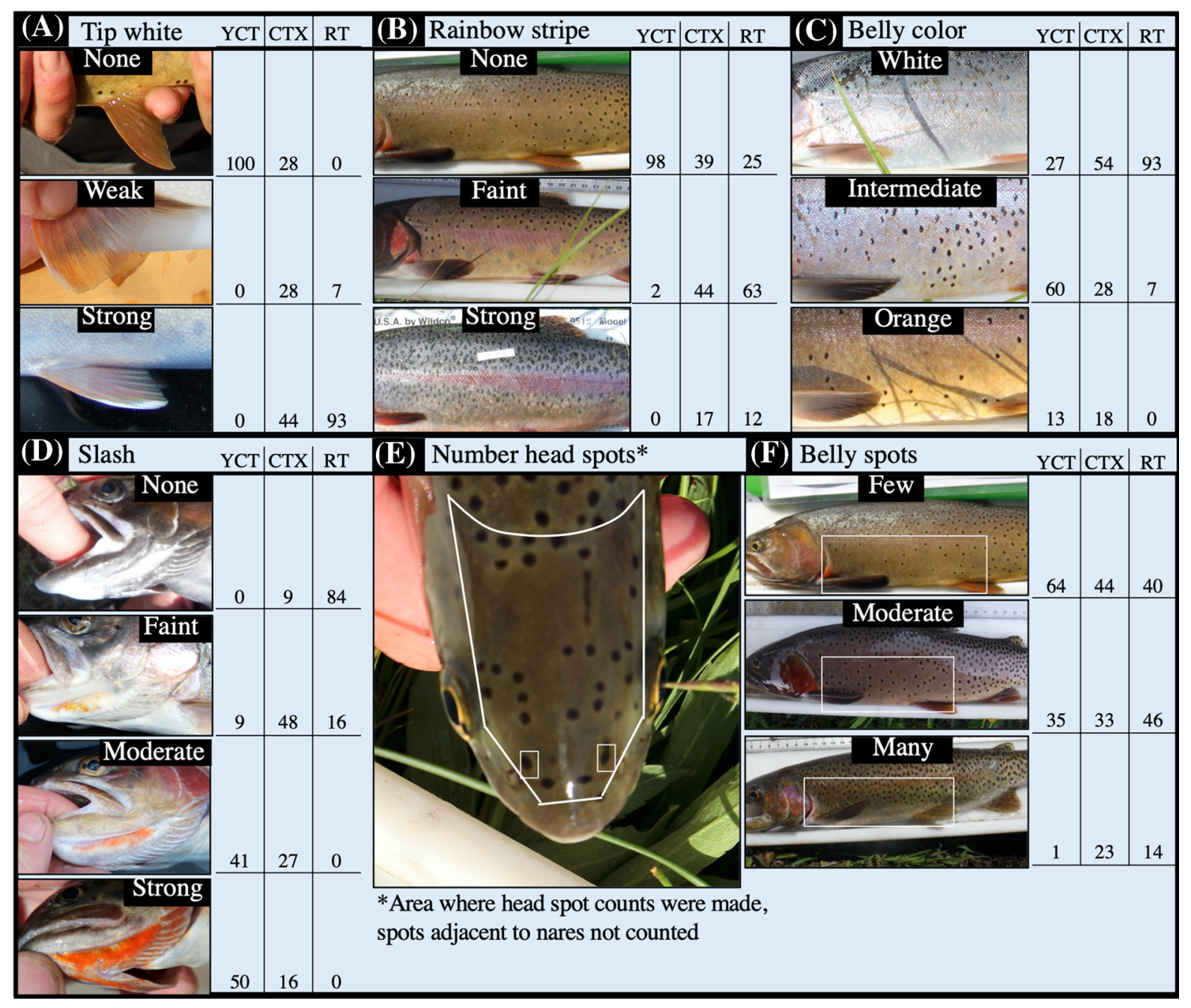

Fig. 2 Morphological features recorded from trout in the field. These exact photographs were included in a laminated reference guide and carried in the field to facilitate consistent attribution. Shown next to each series of photographs $(\mathbf{a}-\mathbf{e})$ is the percent of

morphological assessments. Fish were anesthetized using AQUI-S (New Zealand Ltd., Lower Hutt, New Zealand), fork length was measured (mm, 72-480, mean $=209$ ), a photograph was taken, and a tissue sample was obtained from the upper lobe of the caudal fin and preserved for genetic analysis. Fish were then transferred to a recovery bath where we visually assessed seven morphological features. We used the same features as Meyer et al. (2017a) but recorded them as ordinal scale variables (Fig. 2) rather than binary (i.e., presence/absence). These included white anal fin pigmentation $(0=$ absent, $1=$ weak, genotyped individuals of a given taxa (YCT, CTX, RT) that received each phenotypic score. Panel $\mathbf{f}$ shows the region from which head spot counts were made, and the two spots typically associated with nares that were not included

$2=$ strong), white pelvic fin pigmentation ( $0-2)$, pink 'rainbow' stripe along midline (0-2), orange cutthroat slash on lower jaw (0-3), relative density of spots below the lateral line (0-2), and ventral coloration ( white $=0$, white/orange $=1$, orange $=2$ ). We also counted the number of head spots (Fig. 2). A laminated version of Fig. 2 was carried in the field and used as a reference for the biologist handling the fish and ranking morphological features. Each fish was also identified as YCT, RT, or CTX in the field, based on the general criteria presented in Meyer et al. (2017a). Classification of morphological features and 
fish identification in the field was generally discussed among multiple biologists when identification was uncertain. Because of this, we did not account for the individual biologist handling the fish in our analysis. Photographs provided a means to validate any suspected errors in data recording.

We collected additional information on maxilla length from digital photographs. Based on our observations in the field and prior research (Seiler et al. 2009), we hypothesized that hybrids and RT would have shorter maxillas than YCT. The same biologist analyzed all photographs, and assigned a qualitative score based on the posterior extent of the maxilla relative to the posterior end of the eye $(0=$ maxilla does not extend beyond eye, 1 = maxilla extends slightly past eye, 2 = maxilla extends well beyond eye). Maxilla length ( $\mathrm{mm}$ ) was also measured quantitatively from photographs with the program ImageJ (Abramoff et al. 2004) and expressed as a proportion of fork length for each fish.

Genetic analysis

We used species-diagnostic single nucleotide polymorphism (SNP) loci to estimate the RT ancestry proportion (pRT) of individual fish. This value ranges from 1.00 (pure RT) to 0.00 (pure YCT). Diagnostic SNPs are fixed for one nucleotide at a given locus in a given species (i.e., all RT have a C[cytosine] at a particular locus while all YCT have a T[thymine]), and are widely used in conservation genetics to study hybrid populations. Genotyping was performed at the
University of Montana Conservation Genetics Laboratory using methods and genotyping assays described elsewhere (Bingham et al. 2016). Loci used included SNPs diagnostic for westslope cutthroat trout $(O . c$. lewisi, WCT), YCT, and RT. The set of SNPs (WCT, $\mathrm{YCT}$, and RT) together were used to estimate the genetic contribution of each of the three potentially hybridizing taxa to an individual's genotype (Kalinowski 2010). After screening and removing nondiagnostic loci (Supplementary material), our final marker set included 17 RT, 17 WCT, and 19 YCT diagnostic markers.

\section{Estimation of angler catch}

We used volunteer angler report (VAR) cards and fishing permit sales (2013-2017) to quantify angler effort and catch. Cards are issued to all YNP fishing permit holders, and anglers are asked to report on their fishing experience from a single location only (i.e., one river, stream, or lake), and return the card to YNP officials. Fisheries biologists at YNP process and sort cards according to several reaches on the Lamar River, Soda Butte Creek, and Slough Creek. We used data from the five most commonly fished reaches in the Lamar River watershed (Table 2). For each reach we report the average number of VAR cards returned and catch rates (i.e., number of fish reported caught per angler/trip, by species) during the 2013-2017 fishing seasons.

To account for the population of anglers that fished, but did not return VAR cards, we used a simple
Table 2 Angler catch statistics for five waterbodies in the Lamar River watershed from 2013 to 2017 based on Volunteer Angler Report (VAR) cards. Columns indicate 5-year averages (standard deviation) of reported (followed by $r$ subscript) and extrapolated (ex subscript) statistics including the number of anglers fishing each waterbody, and average number of
Yellowstone cutthroat trout (YCT) and Rainbow trout (RT) and hybrid trout $(\mathrm{CTX})$ combined (RT $+\mathrm{CTX}$ ) caught per angler. The last four columns are 5-year means for overall reported and extrapolated annual catch per waterbody (L, M, and $\mathrm{U}$ indicate lower, middle, and upper (see Fig. 1))

\begin{tabular}{lcccccccc}
\hline Reach & \#Angler & \#Angler & $\begin{array}{l}\text { YCT/ } \\
\text { angler }\end{array}$ & $\begin{array}{l}\text { RT } \\
+ \text { CTX/ } \\
\text { angler }\end{array}$ & \#YCT & \#RT + CTX & \#YCT $_{\text {ex }}$ & \#RT + CTX \\
\hline Lamar R. (L) & $34(10)$ & $914(248)$ & $6.99(1.91)$ & $1(0.46)$ & $243(110)$ & $31(9)$ & $3287(1443)$ & $213(58)$ \\
Lamar R. (M) & $59(16)$ & $1605(446)$ & $9.9(2.96)$ & $0.6(0.7)$ & $568(169)$ & $33(41)$ & $7803(2342)$ & $203(218)$ \\
Slough Cr. (L) & $43(12)$ & $1162(311)$ & $5.01(1.54)$ & $1.38(1)$ & $202(46)$ & $50(17)$ & $2732(409)$ & $348(144)$ \\
Slough Cr. (U) & $41(12)$ & $1117(285)$ & $12.41(3.26)$ & $0.19(0.17)$ & $522(244)$ & $8(7)$ & $6969(2825)$ & $54(48)$ \\
Soda Butte Cr. & $82(13)$ & $2258(495)$ & $13.55(2.07)$ & $0.09(0.04)$ & $1119(314)$ & $8(4)$ & $15,324(4648)$ & $51(22)$ \\
\hline
\end{tabular}


extrapolation procedure to estimate (1) the total number of anglers that fished each reach annually and (2) the total annual catch per reach. The total number of fishing permits sold annually in YNP provides a good estimate of the number of anglers fishing (in all of YNP), and the relative rate at which VAR cards are returned for specific locations provides a rough estimate of how angler effort is distributed across locations in YNP. A demonstration is useful to convey our approach. In 2017 a total of 46,144 permits were issued, 81 anglers returned VAR cards reporting on fishing in Soda Butte Creek, out of an overall 1510 anglers that returned VAR cards. We therefore estimate that in 2017, about $5.36 \%$ of fisherman visiting YNP fished Soda Butte Creek (81 VAR cards for Soda Butte Creek/1510 VAR cards total) so 2475 anglers (5.36\% of 46,144 permits sold) is our extrapolated estimate of the number of fishing trips by anglers in that reach for 2017. An estimate of the total number of fish caught, for that reach, is made by multiplying this number by the average catch per angler during a trip in 2017 (Table 2). As a precaution and to make estimates conservative, we reduced catch rates (fish/trip) by $50 \%$ to account for potential overrepresentation of successful anglers in survey responses, and exaggeration of catch rates (Carline 1972; Sullivan 2003). Following our example scenario, this is 2475 estimated anglers multiplied by a catch rate of $10.53 \mathrm{YCT} /$ trip $(\times 0.50)$ for an estimate of 13,032 fish caught in this reach in 2017. These calculations were compiled for all Lamar River watershed reaches from 2013 to 2017 and reported as five year averages with standard deviations.

To reduce populations via mechanical removal, it is the exploitation rate (i.e., fraction of the population removed) that is relevant rather than absolute numbers. Therefore, we calculated a potential exploitation rate (assuming all fish were kept) for one reach where a mark-recapture population estimate was possible. A two-pass mark recapture population estimate was conducted in July 2016 using raft electroshocking over the approximately 7-km Lamar River (middle) reach. Length-frequency distributions of fish caught by raft electroshocking were similar to the distribution vulnerable to angling (Figure S1), therefore, this population estimate should adequately represent the number of fish vulnerable to angling. This is a reach where RT and CTX are scarce and there were insufficient data to make separate estimates for YCT,
RT, and CTX. We therefore calculated a single estimate representing the entire population of trout by combining all species. Population estimates were made with the Chapman modification of the Peterson formula (Chapman 1951) and 95\% confidence intervals constructed with a Poisson distribution in the FSA package in R (Ogle 2017; R Core Team 2017). We analyzed fish by size group separately $(<250 \mathrm{~mm}$, $250-350,>350)$ to account for differential catchability by size class, and report the total population size estimate. We calculated a potential exploitation rate by dividing the VAR-estimated number of fish caught per year (2013-2017 average) by the population estimate. Values higher than 1.00 suggest fish are captured multiple times annually.

\section{Statistical analysis}

We used recursive partitioning ('rpart' routine in program R; Therneau and Atkinson 2018) to build a classification tree to distinguish native YCT (pRT = 0 ) from fish with any detectable RT ancestry ( $\mathrm{pRT}>0$, including non-hybridized RT). This method uses independent quantitative or categorical variables (in our case the seven morphological features) to divide the dataset into categories and maximize classification success of a single response variable until a specified stopping point (i.e., group size of 10) is reached. Anal fin coloration was almost perfectly collinear with pelvic fin coloration, so this feature was not included in the recursive partitioning analysis. Since our focus was to develop a key specifically for use in the Lamar River watershed, we excluded fish from the Yellowstone River and Ditch Creek, yielding a total of 227 fish for our analysis. To avoid over-fitting, the cost complexity value was set to 0.001 and the classification tree was pruned to minimize the tenfold cross-validated error.

\section{Results}

Based on genetic data, we classified 251 trout as YCT (n = 153), CTX (55), or RT (43) (Table 1, Fig. 3). Individual estimates of $\mathrm{pRT}$ (RT ancestry proportion) of CTX ranged from 0.07 to 0.93 (Fig. 3). Individuals with low pRT (i.e., advanced generation backcrosses to YCT) were relatively scarce. Only two hybrids had $\mathrm{pRT}<0.25$ and only 6 had pRT values $<0.40$ 

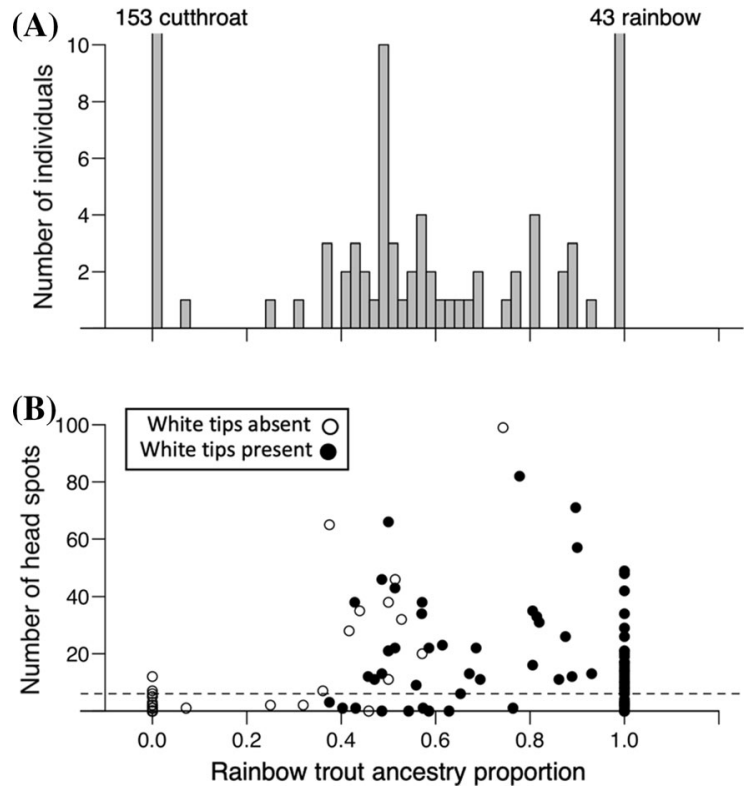

Fig. 3 Distribution of rainbow trout ancestry proportion (pRT) of individual trout used for genotype-phenotype comparison (a), and the relationship between pRT, head spot count, and pelvic fin coloration (panel b). Fish with white tips present on the pelvic fin are shown as closed circles, and open circles show fish with white tips absent from pelvic fins. Fish with white fin tips or $\geq 6$ head spots (points above dashed line) would be classified as hybrids based on our final key. Fish from Ditch Creek are excluded in panel $\mathbf{b}$

(Fig. 3). We detected WCT alleles in only 4 of 251 individuals (2\%), the proportion of WCT ancestry was always less than 0.06 , and all these individuals also had $\mathrm{pRT}>0.40$. We therefore assumed WCT admixture negligibly influenced observed phenotypic variation. Parental RT $(\mathrm{pRT}=1.00)$ were found in only 3 of 15 sites (20\%) and were concentrated in the Buffalo Fork Creek watershed, and two were found in a small intermittent stream (site 3) that was identified as a primary hybrid spawning location in Heim et al. (in press)(Fig. 1). Hybridized fish were present in $40 \%$ of sampled sites (6/15 sites) and concentrated in the lower Lamar River watershed. In contrast, parental YCT were found in $80 \%(12 / 15)$ of sampled sites.

Field based classification success

Assuming 100\% genetic classification accuracy, we correctly field-identified fish in Lamar River sites ( $\mathrm{n}=13$ ) as YCT, CTX, or RT $97 \%$ of the time (220/ 227 correct classifications) by following the general guidelines presented in Meyer et al. (2017a) and the collective judgement of biologists present during sampling. Classifying CTX as RT was the most common misclassification (4/7), which all involved CTX with a high proportion of RT ancestry (pRT > 0.80 ). In a selective removal scenario such mistakes are inconsequential, since the goal is usually to remove fish with any non-native ancestry. Three CTX (pRT $=0.07,0.25$, and 0.46) were misclassified as YCT and would have been mistakenly released into the environment in a culling scenario. Yellowstone cutthroat trout were never mistaken for a CTX or a RT. In sum, only 3 meaningful misidentifications (i.e., releasing fish with RT alleles back into the environment) would have been made out of the 227 fish handled in the Lamar River watershed (1\%).

Outside of the Lamar River watershed we sampled fish from Ditch Creek $(n=23)$ and the Yellowstone River $(n=1)$. Three misidentifications were made that all involved classifying YCT as CTX in Ditch Creek based on notably high head spot counts (see below) for an overall error rate of $13 \%$ for these 24 fish.

\section{Useful morphological features to identify hybrids}

Based on simple summary statistics and visualization of the full dataset (i.e., including all fish, Fig. 3, 4), it was clear that the presence of white anal and pelvic fin tips was the most consistent feature to distinguish hybridized from non-hybridized fish, similar to the findings of Meyer et al. (2017a). One hundred percent of YCT lacked white fin tips on the pelvic fin, in contrast, $72 \%$ of CTX and $100 \%$ of RT had at least faint white pigmentation. Considering RT and CTX together, $84 \%$ of fish that contained at least some RT ancestry had white fin tips and $16 \%$ did not. The results for anal fin coloration are similar, except one YCT had a faint white fin tip (seen as lone red bar amongst yellow bars in Fig. 4). The presence of white fin tips could not be confirmed in the photograph of this fish, suggesting this was a data recording error. Individual fish nearly always received the same classification score for anal and pelvic fins (240/251, 96\%) indicating consistent pigmentation patterns across fins at the individual level.

The presence of pink coloration along the midline and head spot counts also differed among taxa (Figs. 3, 4), but were not as consistent as white fin tips to distinguish taxa. Whereas most RT and CTX 


\section{(A) Genotype}

\begin{tabular}{r||||r|} 
Heterozygosity $(0.00)$ & Heterozygosity $(0.00)$ \\
RT ancestry $(0.00)$ & RT ancestry (1.00)
\end{tabular}

\section{(B) Phenotype}

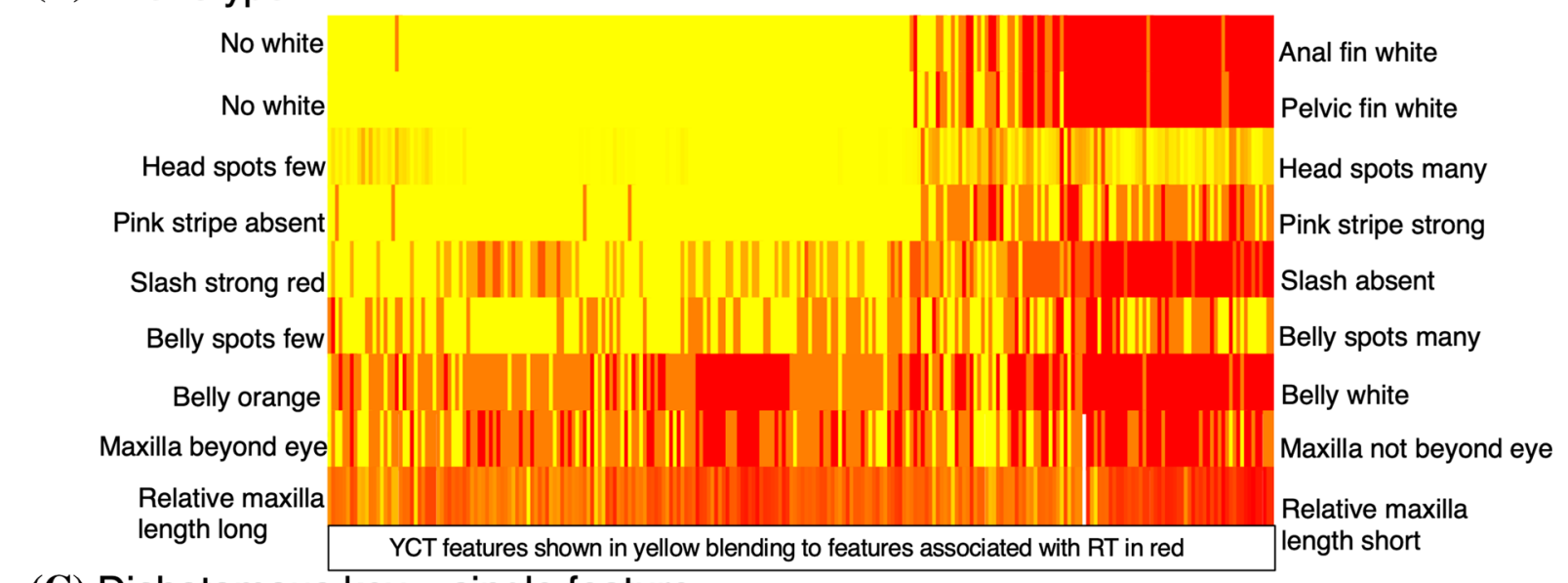

(C) Dichotomous key - single feature

1a. White tip present on pelvic fin..............RT or CTX
1b. White tip absent...................................YCT

$93 \%$ success

15 CTX classified as YCT

\section{(D) Dichotomous key - two features}

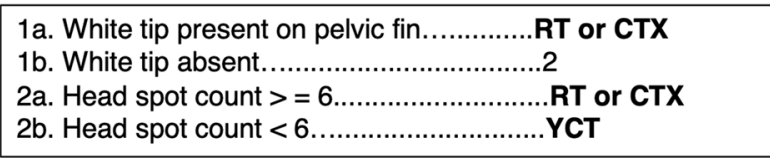

$97 \%$ success

4 CTX classified as YCT

3 YCT classified as CTX
Fig. 4 The correlation between genotype and phenotype of 251 trout including (panel a) Yellowstone cutthroat trout (YCT, yellow), a range of hybrid genotypes (CTX, orange), and Rainbow trout (RT, red). Each fish is represented by a narrow vertical bar with RT ancestry proportion (pRT) represented as a color gradient. Narrow vertical bars in panel b show the morphological data associated with genotyped fish represented in panel a (i.e., narrow columns in panel $\mathbf{a}$ and $\mathbf{b}$ are aligned

had at least a faint pink midline stripe, use of this feature alone would preclude recognition of $39 \%$ of CTX and $25 \%$ of RT. Head spots were useful since YCT had very few (Fig. 3), but fish from Ditch Creek represented a noteworthy outlier population. Here, YCT had an unusually high number of head spots (mean $=11$, range $=0-32, \mathrm{SD}=9$ ), whereas all other YCT included in the dataset had a mean of 0.49 head spots $($ range $=0-12, \mathrm{SD}=1.5$ ). Since fish in Ditch Creek presented no other features indicative of hybridization except head spots, we somewhat conservatively classified them in the field as CTX only if they had an extreme head spot count. Had we used a 5 vertically to represent the same individual fish). Within each row (panel b) ordinal scores for morphological features are represented as a color gradient. Vertical consistency in color between RT admixture (panel a) and morphology (panel b) shows strong relations between genotype and phenotype. Panels c and $\mathbf{d}$ depict classification trees with highest success rate to distinguish YCT from RT and hybrids using a single feature (c) or two features (d) with associated errors shown

head spot rule (Meyer et al. 2017a), 16 (compared to 3, as described above) YCT would have been misclassified as CTX. Maxilla length, ventral coloration, ventral spot density, and lower jaw pigmentation were not particularly useful at distinguishing taxa (Fig. 4).

\section{Classification tree}

The classification trees built with recursive partitioning included only two nodes and very accurately classified fish (Fig. 4). The first dichotomous choice was whether a fish had any white pigmentation on the pelvic fin and yielded 93\% classification success (212 
of 227). In a culling scenario following this single choice key, 15 fish with non-native alleles would be released but no YCT would be killed. These 15 fish were all CTX (i.e., did not include any RT) and had an average pRT of 0.43 (range $=0.07-0.74$ ). Most were near pRT of 0.50 or backcrosses to YCT (i.e., to the left of 0.50 on Fig. 4). The second choice was whether or not the fish had 6 or more head spots, and increased classification success to $97 \%$. In a culling scenario following this key, three YCT would be killed and four fish with RT alleles released into the environment (Fig. 4). The four CTX misclassified as YCT had a mean pRT of 0.27 (range $=0.07-0.45)$.

Variation in morphology with size and admixture

As pRT increased, individual morphology became more similar to parental RT (Figure S2). A visualization of RT and hybrid morphology compared to fork length suggested that larger RT and hybrids tended to have characteristics more similar to YCT (Figure S3, S4). This included stronger cutthroat slash pigmentation and maxillas that more often extended beyond the eye. We also found evidence for ontogenetic changes in YCT morphology. As YCT fork length increased, distinguishing characteristics of YCT typically became more pronounced (Figure S5). Bigger fish had stronger cutthroat slash pigmentation, brighter orange ventral coloration, and maxillas that more often extended past the eye.

Angler effort, catch, and potential exploitation rate

The VAR analysis showed considerable fishing effort and catch in the Lamar River watershed, with an average of 10,514 anglers catching 53,076 trout per year. From 2013 to 2017, an average of 44,008 (range $=42,259-46,144$, SD $=1559$ ) fishing permits were issued annually in YNP. An annual average of 1621 anglers $\quad($ range $=1397-1922, \quad S D=214)$ returned their VAR cards; of these, an average of 384 (range $=286-443, \mathrm{SD}=57$ ) reported fishing in the Lamar River watershed. The average number of reported total fish caught in the watershed from VAR cards was 3894 (3716 YCT, 17 CTX, and 161 RT), with an average catch rate of 10.09 fish per angler/ visit.

Angler use varied considerably among the five reaches; Soda Butte Creek consistently received the most fishing pressure (2258 estimated anglers) and anglers reported the highest catch rates (13.55 fish/ angler) of predominantly YCT (Table 2). Reported numbers of CTX and RT (combined in Table 2) caught were highest in lower Slough Creek and the lower Lamar River (Table 2), which is consistent with recent population genetic sampling (Heim et al., in press). Overall, in these five fishing locations combined, 130 RT and CTX are reported caught annually, with an extrapolated total annual catch of 869 nonnative RT and hybrids.

Comparing the mark-recapture estimate for the middle Lamar River reach, to the estimated number of fish caught in this reach annually, suggests fish are caught an average of 4.95 times annually. The markrecapture population estimate for the middle Lamar River was 1617 (95\% confidence interval 810-2424). A highly conservative estimate of exploitation rate (assuming all fish caught were harvested) is made by comparing reported fish caught to estimated population size. In this scenario, 37\% (601/1617) of fish in the middle Lamar River are captured annually. Comparing estimated population size $(n=1617)$ to the extrapolated angler catch $(n=8006)$ suggests that the number of fish caught is 4.95 times greater than the number of catchable sized trout present in the reach. Applying this to the lower and upper confidence intervals for our population estimate yields potential exploitation rates of 3.30-9.88.

\section{Discussion}

Our study shows that most hybrid trout in Lamar River watershed can be reliably identified by simple visual features. High angler use and catch rates also suggest there is great potential for anglers to harvest a high proportion rainbow trout and their hybrids. Locally, this study guides important decisions related to fisheries management, including public harvest regulations and standardization of hybrid identification in the field for biologists. Since field-based identification of hybrids is commonly used in trend monitoring to guide adaptive management, standardizing identification criteria in the field will lead to more meaningful time-series datasets as different field biologists, technicians, or volunteers participate in sampling programs. This study can also serve as an example of how 
to build classification keys to inform hybrid identification in other hybridizing taxa.

A lack of individuals with low amounts of RT ancestry (pRT) benefitted classification success, since fish with low pRT are harder to accurately identify (Meyer et al. 2017a). Although we had high power to genetically detect pRT levels below $0.05(\sim 95 \%$ probability of detection) few of such fish were encountered suggesting either (1) they are present, but we failed to sample them or (2) they are rare in the watershed. We strongly favor the latter interpretation, since these genotypes were also infrequent in a recent watershed scale genetic assessment (Heim et al. in press). Our classification success results are therefore expected to be representative for the watershed as a whole. In other watersheds (or in other taxa) where late-generation backcrosses with native taxa are more common, hybrid classification by morphology will probably be much more challenging.

The results of our study are of high applied value locally, but we caution that extrapolating results beyond the Lamar River watershed should be done with caution. For instance, our results are consistent with a similar study in Idaho regarding white fin tips (Meyer et al. 2017a), but differ slightly with regard to head spots. Whereas Meyer et al. (2017a) attributed high head spot counts of some YCT to genotyping errors, we encountered a single population (Ditch Creek) that systematically expressed high head spot phenotypes. This is evidence of inter-population variation in YCT morphology, which emphasizes the importance of locally validating phenotype $\times$ genotype relationships. Thus, we suggest that a strict head spot count of 5 (Meyer et al. 2017a) or 6 (our study) should not be used without prior testing.

In classification of other hybridizing taxa there will be similar limitations that depend on the degree of intraspecific variability in morphology and how this relates to the degree of morphological differentiation between species. Focused studies would need to be done to determine how useful morphology is in any new hybrid scenario. However, we found that taking individual photographs and recording morphological features in the field is a low cost and low effort procedure. The entire process added about $30 \mathrm{~s}$ of sampling time for each fish in the field. As researchers continue to perform genetic analysis to evaluate invasive hybridization, the approach demonstrated here could be readily replicated to inform local management needs. In particular, our results highlight the value and relative ease of developing a standardized hybrid identification key.

Using a simple two-step classification key, we successfully classified $97 \%$ of fish that had non-native ancestry. This classification accuracy is similar to other studies (87-94\%, Henderson et al. 2000; Campbell et al. 2002; DeRito et al. 2010; Meyer et al. 2017a) where identification is made based on professional judgement (i.e., without a standard key). We are not aware of other studies of cutthroat trout hybrids that have developed standardized classification keys, but believe this approach has some practical benefits compared to professional judgement. First, the frequency of hybrids captured in surveys is often used as an indicator for monitoring hybridization and the effects of management actions (Kovach et al. 2018), but could be biased by differences in the criteria that biologists use to distinguish hybrids. For example, a time series showing an increasing hybrid proportion in surveys could be indicative of (1) a true increase in the proportion of hybrids or (2) hiring a new biologist with a different criterion for hybrid classification. This would be especially true over long time spans where multiple lead biologists and seasonal technicians are involved in data collection. The same issue could occur for any hybridizing taxa (plants or animals) monitored over time using phenotypic identification without specified guidelines.

Secondly, standardized key development provide a scientific basis for comparing various harvest regulations or agency culling efforts, with an expected rate of error. This type of information could be used to evaluate trade-offs related to genetic management objectives. For example, inadvertently killing a few native individuals (that perhaps have a morphological feature more commonly found in hybrids), might be preferred to releasing hybrids back into the environment. In this case, even 'suspected' hybrids could be removed and recorded as such on data sheets to distinguish them from hybrids that are more confidently identified. In other scenarios where pure individuals are quite rare, and hybrids with predominately native ancestry are still highly valuable for conservation (Allendorf et al. 2001), morphological criteria for culling could be adjusted appropriately.

Whether public harvest can have the desired conservation outcomes depends on (1) anglers' ability to distinguish hybrids, (2) anglers' willingness to 
follow regulations, and (3) whether the resulting exploitation rates will help to reduce hybridization. A white-fin tip criterion for harvest is most promising to use as a single criterion for angler harvest because it is very simple, perfectly separates RT from YCT, and does quite well at separating CTX from YCT. This simplicity is essential because unintentional harvest of native species, because of misidentification, has been problematic in other public harvest scenarios (Schmetterling and Long 1999; Somaweera et al. 2010). We expect a more realistic issue among trout anglers, however, is a lack of harvest by an angler population deeply committed to catch and release. Catch and release fishing is an important tool in fisheries management and many anglers have a deep personal commitment to releasing fish unharmed (Lewin et al. 2006). Many anglers actually prefer fishing for nonnative trout compared to cutthroat trout (Quist and Hubert 2004) and so compliance will depend on angler awareness and understanding of why invasive species removal is important (Simberloff 2014). Clear public communication using positive messages ('save Lamar cutthroat') rather than negative messages ('kill the rainbows') is recommended and can be accomplished via social media, information pamphlets, and web media (Crowley et al. 2017).

Unlike other public harvest programs where a bounty is needed to encourage participation, we estimate that nearly 10,000 anglers fish the Lamar River watershed each year and in some areas fish are probably caught and released several times. If regulations were followed, anglers could clearly remove a substantial number of RT and hybrids. Although the results of our angler effort and exploitation analysis are subject to some uncertainty, these results are supported by anecdotal evidence and the recreational fishing literature. On several occasions during a concurrent fish movement study (Heim 2019), we tagged fish (that were captured by angling) and subsequently recaptured the same fish within hours. Other studies show that fish are caught up to 10 times annually in popular recreational fisheries (Schill et al. 1986; Kozfkay and Dillon 2010). Combined with targeted removal by YNP managers, this level of RT and CTX removal has great potential to help (1) purify native populations by reducing the number of RT and hybrids, and thus the proportion of non-native ancestry in the population, and (2) help to prevent the further spread of hybridization across the watershed. Other studies show that just 1-3 passes with electrofishing equipment annually in streams of similar size to the Lamar River can lead to reductions in the proportion of hybrids in conservation populations (Al-Chokhachy et al. 2014; Meyer et al. 2017b; Kovach et al. 2018). Continued monitoring using morphological criteria coupled with periodic genetic testing will be a useful tool gauge the effects of management actions.

In conclusion, we developed a locally validated key to identify hybrid trout in the field that was highly accurate and quite straightforward to complete. We also used angler survey data to show that a substantial number of invasive trout and hybrids could be removed from this important conservation population by anglers. Together these results strongly support continued efforts to leverage public harvest of invasive trout as a management tool. Any time managers or researchers are performing costly genetic analysis to estimate hybridization, it is worthwhile to collect as much data from these individuals as possible. The morphological component of this study added virtually no extra cost to fieldwork, and was highly useful in the context of local management efforts. We hope this study can serve as an example for other mangers and researchers by demonstrating the usefulness of examining field-friendly methods for hybrid identification.

Acknowledgements We thank the many field technicians and volunteer anglers that helped us sample fish, and William Mans for organizing and annotating photographs. Philip Doepke provided the volunteer angler dataset, and we thank William and Joanne Voigt for their dedication to native trout conservation and public outreach in Yellowstone. We recognize Angela Lodmell and Steve Amish for performing lab work and providing genotypes. We thank Bob Gresswell for discussions about history of the VAR dataset and suggestions for this study. Funding for this research was provided by Yellowstone National Park, Yellowstone Forever, and the Jackson Hole One Fly Foundation.

Open Access This article is licensed under a Creative Commons Attribution 4.0 International License, which permits use, sharing, adaptation, distribution and reproduction in any medium or format, as long as you give appropriate credit to the original author(s) and the source, provide a link to the Creative Commons licence, and indicate if changes were made. The images or other third party material in this article are included in the article's Creative Commons licence, unless indicated otherwise in a credit line to the material. If material is not included in the article's Creative Commons licence and your intended use is not permitted by statutory regulation or exceeds the permitted use, you will need to obtain permission directly 
from the copyright holder. To view a copy of this licence, visit http://creativecommons.org/licenses/by/4.0/.

\section{References}

Abramoff MD, Magelhaes PJ, Ram SJ (2004) Image processing with imageJ. Biophotonics Int 11:36-42

Al-Chokhachy R, Muhlfeld CC, Boyer MC et al (2014) Quantifying the effectiveness of conservation measures to control the spread of anthropogenic hybridization in stream salmonids: a climate adaptation case study. North Am J Fish Manag 34:642-652. https://doi.org/10.1080/ 02755947.2014.901259

Allendorf FW, Leary RF (1988) Conservation and distribution of genetic variation in a polytypic species, the cutthroat trout. Conserv Biol 2:170-184

Allendorf FW, Leary RF, Spruell P, Wenburg JK (2001) The problems with hybrids: setting conservation guidelines. Trends Ecol Evol 16:613-622. https://doi.org/10.1016/ S0169-5347(01)02290-X

Bingham DM, Buckskin P, Osborne H (2016) Isolation, migration, and local recruitment drive persistence of cutthroat trout in tributaries near American Falls Reservoir. North Am J Fish Manag 36:590-605. https://doi.org/10. 1080/02755947.2016.1165765

Campbell MR, Dillon J, Powell MS (2002) Hybridization and introgression in a managed, native population of Yellowstone cutthroat trout: genetic detection and management implications. Trans Am Fish Soc 131:364-375. https://doi. org/10.1577/1548-8659(2002)131\%3c0364:HAIIAM\% 3e2.0.CO;2

Carline RF (1972) Biased harvest estimates from a postal survey of a sport fishery. Trans Am Fish Soc 101:262-266. https:// doi.org/10.1577/1548-8659(1972)101\%5b262:bhefap\% $5 \mathrm{~d} 2.0 . \mathrm{co} ; 2$

Chapman DG (1951) Some properties of hypergeometric distribution with application to zoological census. Univ Calif Publ Stat 1:131-160

Crowley SL, Hinchliffe S, McDonald RA (2017) Conflict in invasive species management. Front Ecol Environ 15:133-141. https://doi.org/10.1002/fee.1471

DeRito JN, Zale AV, Shepard BB (2010) Temporal reproductive separation of fluvial Yellowstone cutthroat trout from rainbow trout and hybrids in the Yellowstone River. North Am J Fish Manag 30:866-886. https://doi.org/10.1577/ M09-006.1

Ertel BD, Heim KC, Arnold JL et al (2017) Preservation of native cutthroat trout in northern Yellowstone. Yellowstone Sci 25:35-41

Flinders J, High B, Keen D, Garren D (2016) Fishery management annual report, South Fork Snake River 2015. Idaho Department of Fish and Game report 16-111, Boise

Frazer TK, Jacoby CA, Edwards MA et al (2012) Coping with the lionfish invasion: can targeted removals yield beneficial effects? Rev Fish Sci 20:185-191. https://doi.org/10.1080/ 10641262.2012.70065

Gresswell RE (2011) Biology, status, and management of the Yellowstone cutthroat trout. North Am J Fish Manag
31:782-812. https://doi.org/10.1080/02755947.2011. 608980

Hansen MJ, Guy CS, Budy P, McMahon TE (2019) Trout as native and non-native species: a management paradox. In: Kershner J, Gresswell RE (eds) Trouts and chars of the World. American Fisheries Society

Heim KC (2019) Mechanisms of rainbow trout hybridization with native cutthroat trout in the Lamar River of Yellowstone National Park. Dissertation, Montana State University

Heim KC, McMahon TE, Kalinowski S, Ertel BD, Koel TM (in press) Abiotic conditions are unlikely to mediate hybridization between invasive rainbow trout and native Yellowstone Cutthroat Trout in a high elevation metapopulation. Can J Fish Aquat Sci. https://doi.org/10. 1139/cjfas-2019-0317

Henderson R, Kershner JL, Toline CA (2000) Timing and location of spawning by nonnative wild rainbow trout and native cutthroat trout in the South Fork Snake River, Idaho, with implications for hybridization. North Am J Fish Manag 20:584-596. https://doi.org/10.1577/15488675(2000)020\%3c0584:TALOSB\%3e2.3.CO;2

Kalinowski ST (2010) How to use SNPs and other diagnostic diallelic genetic markers to identify the species composition of multi-species hybrids. Conserv Genet Resour 2:63-66. https://doi.org/10.1007/s12686-009-9146-0

Kovach RP, Al-Chokhachy R, Stephens T (2018) Proactive rainbow trout suppression reduces threat of hybridization in the Upper Snake River Basin. North Am J Fish Manag 38:811-819. https://doi.org/10.1002/nafm.10177

Kozfkay JR, Dillon JC (2010) Creel survey methods to assess catch, loss, and capture frequency of white sturgeon in the snake river, idaho. North Am J Fish Manag 30:221-229. https://doi.org/10.1577/M09-064.1

Lewin WC, Arlinghaus R, Mehner T (2006) Documented and potential biological impacts of recreational fishing: insights for management and conservation. Rev Fish Sci 14:305-367. https://doi.org/10.1080/10641260600886455

Mack RN, Simberloff D, Lonsdale MW, Harry E (2000) Biotic invasions: causes, epidemiology, global consequences, and control. Ecol Appl 10:689-710. https://doi.org/10.1890/ 1051-0761(2000)010\%5b0689:bicegc\%5d2.0.co;2

Meyer KA, Kennedy P, High B, Campbell MR (2017a) Distinguishing Yellowstone cutthroat trout, rainbow trout, and hybrids by use of field-based phenotypic characteristics. North Am J Fish Manag 37:456-466. https://doi.org/ 10.1080/02755947.2017.1280572

Meyer KA, Kennedy P, High B, Campbell MR (2017b) Purifying a Yellowstone cutthroat trout stream by removing rainbow trout and hybrids via electrofishing. Trans Am Fish Soc 146:1193-1203. https://doi.org/10.1080/ 00028487.2017.1362470

Nicieza AG (1995) Morphological variation between geographically disjunct populations of Atlantic salmon: the effects of ontogeny and habitat shift. Funct Ecol 9:448-456

Nuñez MA, Kuebbing S, Dimarco RD, Simberloff D (2012) Invasive species: to eat or not to eat, that is the question. Conserv Lett 5:334-341. https://doi.org/10.1111/j.1755263X.2012.00250.x

Ogle DH (2017) FSA: fisheries stock analysis. R package version 0.8 .17 
Pimentel D, Zuniga R, Morrison D (2005) Update on the environmental and economic costs associated with alien-invasive species in the United States. Ecol Econ 52:273-288. https://doi.org/10.1016/j.ecolecon.2004.10.002

Quist MC, Hubert WA (2004) Bioinvasive species and the preservation of cutthroat trout in the western United States: ecological, social, and economic issues. Environ Sci Policy 7:303-313. https://doi.org/10.1016/j.envsci.2004.05.003

Schill DJ, Griffith JS, Gresswell RE (1986) Hooking mortality of cutthroat trout in a catch-and-release segment of the Yellowstone River, Yellowstone National Park. North Am J Fish Manag 6:226-232. https://doi.org/10.1577/15488659(1986)6\%3c226:HMOCTI\%3e2.0.CO;2

Schmetterling DA, Long MH (1999) Montana anglers' inability to identify bull trout and other salmonids. Fisheries 24:24-27. https://doi.org/10.1577/1548-8446(1999)024\% 3c0024:MAITIB\%3e2.0.CO;2

Seiler SM, Gunnell K, Ptacek MB, Keeley ER (2009) Morphological patterns of hybridization between Yellowstone cutthroat trout and introduced rainbow trout in the South Fork of the Snake River watershed, Idaho and Wyoming. North Am J Fish Manag 29:1529-1539. https://doi.org/10. 1577/M08-128.1
Simberloff D (2014) Biological invasions: what's worth fighting and what can be won? Ecol Eng 65:112-121. https://doi. org/10.1016/j.ecoleng.2013.08.004

Somaweera R, Somaweera N, Shine R (2010) Frogs under friendly fire: how accurately can the general public recognize invasive species? Biol Conserv 143:1477-1484. https://doi.org/10.1016/j.biocon.2010.03.027

Sullivan MG (2003) Exaggeration of walleye catches by alberta anglers. North Am J Fish Manag 23:573-580. https://doi. org/10.1577/1548-8675(2003)023\%3c0573:EOWCBA\% 3e2.0.CO;2

R Core Team (2017) R: a language and environment for statistical computing. R Foundation for Statistical Computing, Vienna, Austria. http://www.R-project.org/

Therneau T, Atkinson B (2018) rpart: recursive partitioning and regression trees. $\mathrm{R}$ package version 4.1-13. https://CRAN. $\mathrm{R}$-project.org/package=rpart

Publisher's Note Springer Nature remains neutral with regard to jurisdictional claims in published maps and institutional affiliations. 